\title{
DEĞERLENDIRMELER
}

TÜRK DÜNYASI, Dil ve Edebiyat Dergisi/TURKISH WORLD, Journal of Language and Literature

Issue: 43 (Bahar-Spring 2017) - ISSSN: 1301-0077 Ankara, TURKEY

DOI Numarası/DOI Number: 10.24155/tdk.2017.21

\section{SEYIT ASKAROVICC KASKABASOV VE KAZAK FOLKLOR ARAŞTIRMALARINDAKİ YERİ}

Ekrem BEYAZ*

Seyit Askaroviç Kaskabasov, 24 Haziran 1940 senesinde bir Doğu Kazakistan şehri olan Semey'de [Semipalatinsk] dünyaya gelmiştir. 1959-1964 yılları arasında Abay Üniversitesi Filoloji Fakültesinde lisans eğitimini; 1964-1967 yılları arasında M. O. Avezov Üniversitesi Edebiyat ve Sanat Enstitüsünde ise lisansüstü eğitimini tamamlamıştır. 1970 senesinin aralık ayından itibaren Kazakistan SSC İlimler Akademisi Sosyal Bilimler Enstitüsünde bilimsel işler sekreterliğini yürütmüştür. Aynı görevi 1978 senesinin ağustos ayından 1981 senesine kadar M. O. Avezov Üniversitesi Edebiyat ve Sanat Enstitüsünde yürütmüştür. 1982-1983 yılları arasında SSCB İlimler Akademisi Başkanlık Kurulunca araştırma faaliyetlerinde bulunması amacıyla M. Gorkiy Dünya Edebiyatı Enstitüsünde görevlendirilmiştir.

1984-1988 y1lları arasında M. O. Avezov Üniversitesi Edebiyat ve Sanat Enstitüsünde bölüm başkanlığı görevinde bulunmuştur. 1988'den 1991'e kadar İdeolojik Çalışmalar Bölümünde danışmanlık ve Kazakistan Komünist Partisi Merkez Komitesine bağlı Siyasi Hareketler Sosyolojisi Merkezinin müdürlügünü yapmıştır. 1989'da Moskova Devlet Üniversitesinde filoloji alanında doktora tezini savunmuştur. 1991-1992 yıllarında Kazakistan Cumhuriyeti Devlet Başkanlığı ve Bakanlar Kurulu bünyesindeki Eğitim, Bilim, Kültür ve Spor Dairesi başkan yardımcıllğı görevinde bulunmuştur.

1992-1994 yıllarında Kazakistan Cumhuriyeti Bakanlar Kuruluna bağl1 Yüksek Atestasyon Komisyonu başkanlığını ve 1995-1997 yılları arasında M. O. Avezov El Yazmaları Merkezinin müdür yardımcıllğını ve müdürlüğünü

AKDTYK Uzman Yardımcısı, ekrembeyaz@live.com. 
yapmıştır. 1993 senesinde kendi teşebbüsleriyle BDT ülkeleri dâhilinde oluşturulmuş Milletlerarası Devlet Atestasyon Komisyonları Teşkilatı [MDAKT (МАГАТ)] kurulmasını sağlamış ve bu kuruluşun ilk başkanı olmuştur.

1997'den 2001'e kadar "Evraziystvo" adlı ilmî araştırmalar merkezinin yöneticiliğini ve Astana'da bulunan L. N. Gumilev Devlet Üniversitesi Şarkiyat Fakültesi dekanlığını yapmıştır. 2001 senesinin ekim ayından 2012'ye kadar M. O. Avezov Üniversitesi Edebiyat ve Sanat Enstitüsünün başkanlığını yapmıştır. Bulunduğu görevler dışında, S. A. Kaskabasov ilmî faaliyetlerle de meşgul olmuştur. Esasen halk bilimci olan bilim adamı; edebiyat, sanat tarihi, tarih, etnoloji, dil bilimi ve kültür araştırmaları gibi geniş bir ölçekte sahada çalışmalarda bulunmuştur. Araştırma alanı oldukça geniş olan Kaskabasov, Asya, Amerika, Avustralya ve Afrika coğrafyalarını ele alan çeşitli kadim ve çağdaş mitoloji araştırmaları; Eski Hint, Mısır ve kadim Ortadoğu uygarlıklarına ait folklor ve edebiyat araştırmaları; Antik Yunan ve Roma medeniyetleri ve aynı şekilde Orta Çağ Avrupası'na ait eserler üzerine araştırmalar yapmıştır. Yürüttüğü çalışmalarla Kazak folklorunun umumi tabiatını ve millî kimliğini ortaya koymayı hedeflemiş ve Kazak folklorunun ve edebiyatının dünya kültürünün bir parçası olduğunu ortaya koymayı başarmıştır.

Çok yazarlı eserler içinde yeni edebî kuramlardan faydalanılarak oluşturulmuş Kazak Edebiyatı Tarihi, Kazak Folkloristiği Tarihi, SSCB Halklarının Folkloru ve Günümüz, SSCB Halklarının Folklor Sahnesi, Azerbaycan-Kazakistan Edebî Bağ adlı yapıtlarda S. A. Kaskabasov'un ismi geçmektedir. M. Gorki Dünya Edebiyatı Enstitüsünde kıdemli araştırmacı vasfiyla çalıştığ1 yıllarda Kazak milleti için büyük ehemmiyeti haiz olan 1500 yıllık "Kozı Korpeş-Bayan Sulu" ve "Kız Jibek" destanları üzerinde araştırmalar yapmış ve metinleri derleyip Rusçaya çevirerek Moskova'da yayımlamıştır. Moskova'da ayrıca Kazakça-Rusça Sözlük de hazırlamıştır. Kırk yılı aşkın bir süredir Kazak folklorunu ve öncelikli olarak Kazak halk şiirini inceleyen Kaskabasov, tarihî gelişme nazariyelerinden yararlanarak ve sözlü Kazak edebiyatını sınıflandırarak Kazak halkının gelenek, görenek, inanç ve kutlama törenleri üzerine de çalışmıştır

Bugün alanında ender çalışmalardan biri olan 1972 'de tamamladığı $\mathrm{Ka}$ zak Büyücülük Hikâyesi adlı ilk monografisini bitirme tezi olarak yazmıştır. $\mathrm{Bu}$ eser, Kazak folklor araştırmalarında türe yönelik ilk esaslı çalışma olarak kabul edilmektedir. 1984'te Kazakça olarak yayımladığı Kazak Halk Şiiri adlı eseri, Kazakistan İlimler Akademisinin en büyük ödülü olan Çokan Valihanov Ödülü’ne layık görülmüştür. Aynı yıllarda, 1990 senesinde yayımlanmış Kazak Folkloristiğinin Tarihi (Ekim Devrimine Kadar) adlı müşterek monografiye katkılarda bulunmuştur. 1990 yılında yayımladığı Kazak Mensur Masalları adlı eseri 1992'de Kazakistan Cumhuriyeti Devlet Ödülü almıştır ve 
bu çalışması bilim adamının Kazak folkloru üzerine yaptığı araştırmaların en iyilerinden biri olarak kabul edilmektedir.

S. A. Kaskabasov 2000 yılında iki ciltlik araştırma eseri olan Zolotaya Jila'yı, 2002 yılında yine bir araştırma eseri olan Jazazık'1 yayımladıktan sonra birtakım bilimsel çalışmalarının yer aldığı Elzerde (2008) ve Oyöris (2010) adlı kitaplarıyla bazı makalelerini peşi sıra Kazak okuyucusuyla buluşturmuştur.

S. A. Kaskabasov'un doğrudan idaresinde 2013 yılında 100 cilt olarak tamamlanan Babalar Sözi adlı eser, Sovyetler sonrası Türk cumhuriyetlerinde ve bütün Türkiyat camiasında ölçek olarak neşredilmiş en geniş muhtevalı eserlerdendir.

Eser, dil bilimi, tarih, etnografya, insan tipleri üzerine genel yorumlar getirmesi bakımından geniş kapsamlı bir çalışmadır. Her bir ciltte İngilizee ve Rusça özet kısımları ve arkaik, dinî vs. kavramların verildiği sözlük mevcuttur.

Masal ve destan geleneğindeki alışılmış kalıplardan ayrılan bir grup mensur folklor türünü bu bilim dalına kazandırmıştır ve sistematik bir bütün olarak böyle bir grup daha önce hiç kimse tarafından ele alınmamıştır. Bu bakımdan, her bir türü ayrı ayrı araştırmış, iç değişkenliklerini belirlemiş, ortak ve ayırt edici özelliklerini ortaya koymuş ilk bilim adamıdır. Kazak folklorunda mitoloji, hikâye, äpsana (efsane), hikâyat (dinî hikâyeler) ve a ızzdı nesir olarak da adlandırılan ayız (tarihî menkıbeler) gibi türler olduğunu belirlemiş ve bu türleri art zamanlı ve eş zamanlı bölümler hâlinde işleyerek ayızdık nesir'in basit biçimden bedii biçime nasıl evrildiğini gözlemlemeye çalışmıştır. S. Kaskabasov, dünya mitolojisinden örneklerle Kazak mitolojisini mukayeseli ve tipolojik olarak kapsamlı bir şekilde ele almış ve böylelikle Kazak mitolojisinin genel hatlarını ortaya çıkardığı gibi dünya mitolojisindeki yerini de göstermiştir.

Bilim adamı Kazak masallarını da incelemiştir. Mevcut 3 masal türüne gïbrattık (ders veren kısa hikâye) ve sıkak (hiciv) olmak üzere 2 tür daha eklemiş ve bu 5 türü ertegilik (nesir şeklinde masal) olarak nitelendirmiştir. Aynı zamanda a $ı z d l k$ ve ertegilik terimlerini halk nesri içindeki türler arasına sokarak Kazak edebiyatına yeni terimler kazandırmıştır.

S. Kaskabasov, Kazak Edebiyatı Tarihi'nin ilk 10 cildi olan Kazak Folkloristiği Tarihi adlı çok yazarlı eserin yazılmasında da araştırmanın telakkisini, usulünü ve yapısını belirleyip bir cildini de bizatihi hazırlayarak mühim bir görev üstlenmiş̧ir. Bu eserdeki bölümlendirilmeyi Kazak folklorunu "Kadim Zamanlardaki Ruhanî Kültür", "Orta Çağ Folkloru” ve "Modern Folklor" olarak üçe ayırarak yapmıştır. Böylesine bir sınıflandırılma Kazak folkloristiğin- 
de ilk defa yapılmıştır ve her 3 dönemde türleri ortaya çıkış, gelişme, dönüşme ve sanat özelliklerine nasıl ulaştıkları bakımından incelemiştir. Bu çalışmadaki başka bir ilk ise, Sovyetler Birliği zamanında yasaklı olan büyücülük folklorundaki alğıs (hayır duası), jarapazan (ramazan duaları), bata (dua), karğıs (beddua), ant (ant), baksı sarını (bahşı ezgisi) gibi çeşitli mefhumların bu hacimli eserde incelenmiş olmasıdır.

S. A. Kaskabasov, Kazak folklorunun poetikası üzerine yaptığı incelemeler sonucu folklor yapısında iç içe geçmiş halkaların olduğunu gözlemlemiş ve önceleri sadece 3 tür halkanın olduğu düşünülen Kazak halk folkloristiğinde hikâye, biyografik, genetik, tarihî ve coğrafi olmak üzere 5 tür halka olduğunu tespit etmiştir.

Kazak folklorunda önceleri 4 alt başlığı olan epik tür tasnifine balad ve dastan şeklinde iki alt başlık daha eklemiştir. Moskova'da yayımladığı $A v$ rasya Halklarının Destanları adlı kitapta "Kozı Korpeş-Bayan Sulı" ve "Kız Jibek" destanlarını farklı bir bakış açısıyla inceleyerek, vakaları destanların yazıldığ 1 zamandaki kültür ortamına göre değerlendirerek bu destanlardaki Kodar ve Bekejan figürlerini yeniden yorumlamıştır.

15.-18. yy. Kazak Edebiyatı adlı eserinde bu dönemde yaşamış 'jırav'ların (ozan) ve 'akın'ların (âş̧k) üretkenliğinin özünün ne olduğunu yeni ve farklı bir açıdan ele almıştır. Bu eserinde bilim adamı 'jırav'ların Cengiz Han zamanında ve Kazak Kağanlığı'nda basit bir şair olmaktan öte, kimi zaman savaşlara giden batır, kimi zaman siyasi eleştirmen ve kimi zaman da hükümdarın danışmanı olduklarını göstermiştir.

19. yy. şiirini Mahambet Ötemisulı ve Abay Kunanbayulı üzerinden ele almıştır. Mahambet'in şiir anlayışını farklı bir açıdan incelemiştir. Bilim adam1, Mahambet'in öncesindeki şiir geleneğini Hanlık şiiri olarak görmektedir. Aynı ayrıma Mahambet' in Jangir Han Ordası'nda görev yaptığ 1 yıllarda verdiği eserler ve Han'dan ayrildıği yıllar sonrasında verdiği eserler de uğrar.

S. A. Kaskabasov Abay üzerine de birçok çalışma yapmıştır. Örnek olarak, Abay'ın şiirlerinde, Kazak folklorundaki konularla edebî sanatların yanı sıra Doğu edebiyatı ve folklorunun konularını kullandığını saptamıştır. Abay'ın “İskender" şiirindeki konu örgüsünün Talmud'daki kıssalara uzandığını tespit etmiş ve onun bir Rönesans sanatçısı olarak değerlendirebileceğini iddia etmiştir. Abay'ın üslubunda, yenilikçilik, gerçekçilik, eleştiri ve lirizm olmak üzere 4 esas unsurun bulunduğunu belirlemiştir. Abay'ın üslup ve poetika (vezin, kafiye, kıta, betimleme vs.) ile ilgili getirdiği birçok yeniliğin dışında Kazak edebiyatına baladı da getirdiğini belirlemiştir. Abay'ın, atasözleri ve deyimlerdeki tercüman kimliğiyle Kazak etnojenezine de ulaştı̆̆ını belirlemiştir. S. A. Kaskabasov, folkloristik alanında Jambıl Jabayev'in eserlerinden yaptığı seçmeleri bir kitap hâline getirip Rusça yayımlayarak yazar üzerine 
yapılan çalışmalara da katkıda bulunmuştur. Bilim adamı hazırladığı bu eserde ön söz yazmış ve önceki jıraw ve akın'larla kıyaslamalarda bulunarak Jambıl Jabayev'in eserlerinde "jırşı" (hikâyeci), "jırav" (ozan) ve "aytıs akını" (atışma yapan usta âşık) olmak üzere 3 tip sözlü edebiyat kimliğini kendisinde topladığıını görmüştür.

A. S. Kaskabasov Yusuf Has Hacip, Kâşgarlı Mahmud, Ahmed Yesevî, Edip Ahmed Yüknekî hakkında araştırmalar yaparak yazılı edebiyat alanında bilhassa eski Türkçe metinleri çalışmıştır. Yeni edebiyatla ilgili olarak umumiyetle Abay Kunanbayulı ve onun sanatı üzerinde çalışan Kaskabasov'un, Sovyetler Birliği döneminde yasaklı olan Şangerey Bukeyev, Şakerim Kudayberdiyev, Meşhur Yusuf Köpeyev ve Nurlan Sekenoviç Ormanbekov'la da ilgili çalışmalar yaptığı görülmektedir.

S. A. Kaskabasov'un teşebbüsüyle 20 ciltlik Adebi Jadigerler (Edebî Yadigârlar) adlı eserin yazılmasına başlanmış ve başlangıçtan 20. yüzyıla kadar olan bir zaman aralığını kapsayan eser yayımlanmıştır. Sakalar, Hunlar ve ilk Türk yazılı anıtlarından 19. yüzyıl metinlerine kadar birçok konu bu eserde ele alınmıştır. Rabguzî, Babür Şah, Muhammed Haydar Duvlati, Celayirî gibi mühim şahsiyetlere ait eserler ilk kez bu eserle Kazak dilinde yayımlanmıştır.

Sanat tarihi alanında da araştırma faaliyetlerinde bulunan bilim adamı, folkloru bütün modern sanatların temeli olarak kabul etmektedir. Ona göre, Kazakların 20. yüzyıl öncesindeki sanat anlayışında da bir nevi tiyatro geleneği bulunmaktadır. S. A. Kaskabasov, Kazak folklorundaki bu tiyatro yapısını: 1) Takvim esasl ve gündelik ananevi folklor sanatı ve drama, 2) Folklor ve drama yapıtlarınin hususi biçimleri ve 3) Profesyonel tiyatronun ve drama sanatının ilk biçimleri olarak üçe ayırmaktadır. Bilim adamı ilk kısma her nevi gündelik törenlerde, düğün ve cenaze âdetlerinde yeri olan sözlü edebiyat biçimlerini dâhil etmekte ve bunların günlük ihtiyaçları karşılamaya yönelik olmalarından dolayı belirli bir estetik boyutunun olduğundan bahsetmekte, ikinci kısma birçok farklı boydan ve bölgeden insanların katıldığ 1 büyük halk toplantılarında ve muhtelif kutlamalarda sahnelenen eğlence oyunlarını ve folklor temsillerini dâhil etmekte, üçüncü kısma da 20'nci yüzyıl başlarında ortaya çıkmaya başlayan tiyatro takımlarının yanı sıra halk şölenlerine katılan sal seri adlı âşıkları ve acemi ve mesleki eğlencecileri dâhil etmektedir.

Folklor sanatının tabiatına ilişkin eserlerinde S. A. Kaskabasov, Kazak sözlü edebiyatında tragedyanın ve komedyanın birçok folklorik biçiminin var olduğunu kanıtlamıştır. M. Avezov'dan Enlik-Kebek, Gabit Musirepov'dan Kozı Korpeş-Bayan Sulı ve Klz Jibek isimli eski oyunları incelemiş ve bu eserlerdeki benzerlikleri, farklılıkları, betimlemeleri ve yazarların veya tiyatro yönetmenlerinin ideolojik veya sanat kaygılarından ortaya çıkan farklılaşmaları belirlemiştir. Farklı sanat türlerindeki folklor unsurlarını gözlemlemiş 
ve bunların son yüzyılda Kazakların manevi hayatında ne gibi değişikliklere sebep olduğunu ortaya koymaya çalışmıştır. Bütün bu müşahedeler neticesinde, folklorun yalnızca birtakım ananevi faaliyetler bütünü olmadığını; aynı zamanda sinema, tiyatro, müzik vb. modern sanatların da kaynağını teşkil ettiğini ve bunlarla bir bütünlük oluşturduğunu belirtmiştir.

S. A. Kaskabasov'un yirmi ikisi şahsi monografilerinden ve kitaplarından oluşmak üzere 400 kitabın hazırlanmasında emeği geçmiştir. Eserleri Türkçe, İngilizce, Rusça, Korece ve Çince olarak yayımlanmıştır. Kendi idaresiyle ve doğrudan katkılarıyla folklor ve edebiyat monografilerinden oluşan ve neticesinde 151 cilt kitap yayımlanan "Kültürel Miras" adlı devasa bir projede bulunmuştur. 100 ciltlik Babalar Sözi, 20 ciltlik Adebi Jadigerler, 10 ciltlik Kazak Adebiyetinin Tarihi, 4 cildi Kazakça ve 3 cildi Rusça olan Kazak Öneriniy Tarihi, 8 ciltlik Kazak Muzikası: Antoloji, 3 ciltlik Dünya Folkloru ve 3 ciltlik Dünya Edebiyatı bu proje dâhilinde oluşturulmuştur.

M. O. Avezov Edebiyat ve Sanat Enstitüsünde görev yaptığı yıllarda enstitü tarafından M. Avezov'un eserlerini içeren 50 ciltlik külliyat ile A. Baytursınov ve M. Duvlatov'un eserlerini içeren beşer ciltlik iki ayrı eserin yanında otuzu monografi olmak üzere M.Ötemisov ile başka yazarların yayınlarını içeren 4 ciltlik derleme ile çeşitli bildiri ve araştırmalardan oluşan toplam 350 eser yayımlanmıştır.

S. A. Kaskabasov, Kazak folkloru alanında çalışmalar yapacak bilim insanlarının yetiştirilmesine de büyük önem vermiştir. 13 yüksek lisans, 29 doktora tezi danışmanlığı yapmıştır. Milletlerarası Sözlü Edebiyat Araştırmacıları Derneği (Finlandiya), Cengiz Han Dünya Akademisi (Moğolistan), Aytmatov Milletlerarası Akademisi (Kırgızistan) gibi milletlerarası cemiyetlerde ve eğitim kurumlarında kongre, sempozyum ve konferanslara sıklıkla katılmaktadır. Folklor, edebiyat ve sanat alanında yaptığı mühim katkılar sebebiyle Velihanov Ödülü, Kazak Sanat Akademisi Ödülü, Kazakistan Cumhuriyeti Devlet Ödülü, Milletlerarası Jambıl Vakfı Ödülü vb. birçok ödüle layık görülmüştür.

\section{Kaynaklar}

ORAZBEK, M. (2015), Akademik S. A. Kaskabasovtın ğılımi mektebi=Nauçnaya Şkola Akademika S. A. Kaskabasova=Scientific School of S. A. Kaskabasov, Almat1, Arda.

NISANBAYEV, A. N.-BURKITBAY, A. (2005), "Kaskabasov", Kazahstan. Natsionalnaya Entsiklopediya, Cilt 3, s. 177-8, Almatı, Kazak Entsiklopediyası.

ANANYEVA, S. (2015, Eylül 3), Folklorist mirovogo masştaba, Alıntı: http://www.kazpravda. $\mathrm{kz} /$ fresh/view/folklorist-mirovogo-masshtaba/. 